\title{
Erector spinae plane block as rescue analgesia in gestational week 16
}

\section{6. gestasyonel haftada uygulanan kurtarıcı analjezi amaçlı erektör spina plan bloğu}

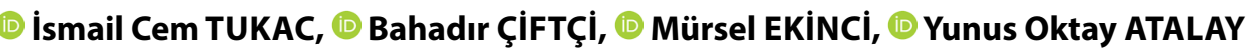

To the Editor,

Nonobstetric operations are sometimes necessary during pregnancy, with an estimated incidence of about $2 \%$ among pregnant women. In recent years, laparoscopic procedures have been preferred for abdominal surgery in pregnancy, as these are well tolerated by both the mother and fetus during all trimesters of pregnancy. ${ }^{[1,2]}$ Postoperative pain management is important for pregnant patients undergoing a nonobstetric procedure, as pain may increase the risk of premature labor. For pain management during pregnancy, paracetamol is the drug of choice, and nonsteroidal anti-inflammatory drugs should be avoided. Regional blockade techniques are preferred, as they reduce the risk of opioidinduced hypoventilation. ${ }^{[3]}$ Among regional block techniques, ultrasound (US)-guided erector spinae plane block (ESPB) is a novel interfacial plan block, which was first described by Forero et al. in 2016 as a treatment for thoracic neuropathic pain. ${ }^{[4]}$ There are a number of case reports in the literature on the analgesic effect of ESPB after laparoscopic surgeries. ${ }^{[5]}$ To our knowledge, this is the first report of ESPB performed for a pregnant patient as postoperative rescue analgesia. Written informed consent was obtained from the patient for this report.

Herein, we describe successful postoperative pain management using ESPB in a 34-year-old, American Society of Anesthesiologists physical status I woman at 16 wk of gestation who had laparoscopic surgery for a gastrointestinal stromal tumor under general anesthesia. After successful and uncomplicated surgery, $1 \mathrm{~g} / \mathrm{kg}$ of paracetamol (IV) was administered $20 \mathrm{~min}$ before the end of the surgery for postoperative pain management. Nonsteroidal anti-inflammatory drugs and opioids were avoided because of the pregnancy.

Although paracetamol was administered, the patient's postoperative visual analog score (VAS) was 8 in the postanesthesia care unit. Thus, we decided to perform single-shot bilateral ESPB as rescue analgesia. The patient was placed in the sitting position (Fig. 1a). After local anesthetic infiltration of the skin under aseptic conditions, a linear US probe $(12 \mathrm{MHz})$ with a sterile sheath was placed in a sagittal paramedian orientation at the level of the T7 transverse process. After visualizing the trapezius, rhomboid major, and erector spinae muscles superficial to the hyperechoic transverse process shadow (Fig. 1b), a 22-gauge, 50-mm block needle (Braun Stimuplex Ultra 360; Germany) was inserted within the interfacial plane between the rhomboid and erector spinae muscles in a caudal-to-cephalad direction. Then, $2 \mathrm{ml}$ of saline were injected to confirm the proper injection site, followed by administration of a $20 \mathrm{ml}$ dose of $0.25 \%$ bupivacaine, injected bilaterally (Fig $1 \mathrm{c}$ ) ( 40 $\mathrm{ml}$ in total). The pain subsided, the VAS score was 2 points, and the patient appeared relaxed $10 \mathrm{~min}$ after the block procedure. A dose of $1 \mathrm{~g}$ of paracetamol was then administered every $8 \mathrm{~h}$. The maximum VAS score that the patient experienced was 2 over a $36-\mathrm{h}$ period. No other analgesic was required.

Department of Anesthesiology and Reanimation, İstanbul Medipol University Faculty of Medicine, İstanbul, Turkey

Submitted: 27.05.2019 Accepted after revision: 24.06.2019 Available online date: 26.06.2019

Correspondence: Dr. Bahadır Çiftçi. İstanbul Medipol Üniversitesi Tıp Fakültesi, Anesteziyoloji ve Reanimasyon Anabilim Dalı, İstanbul, Turkey. 

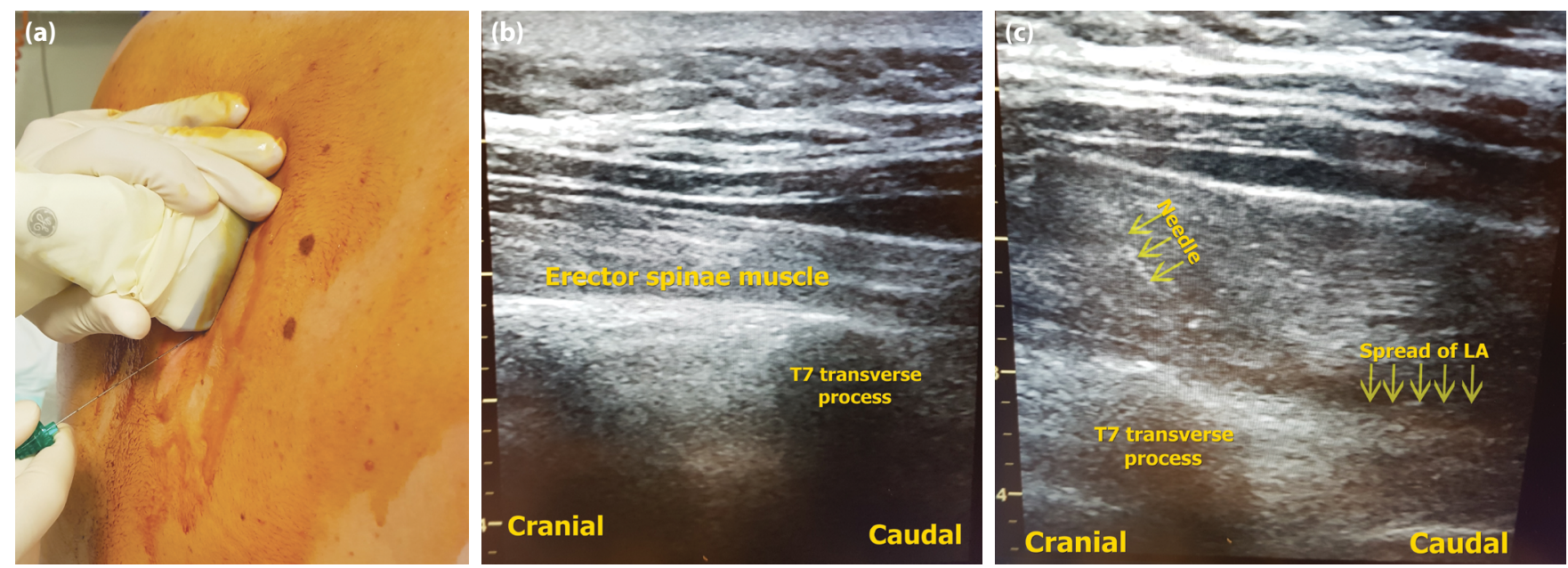

Figure 1. (a) Ultrasound and patient positioning under aseptic conditions for block preparation. (b) Sonographic anatomy of the block. (c) The needle direction in a cranio-caudal way and spread of local anesthetic in the fascia of erector spina muscle.

A previous case report described the use of ESPB during pregnancy in a 13-wk pregnant woman who complained of chronic spinal-related pain. ${ }^{[6]}$ In this case report, the patient received paracetamol and physical therapy. However, she was unable to tolerate the physical therapy and required conservative therapies. Following the failure of these conservative therapies, ESPB was performed. The patient was symptom free 12 wk after the ESPB, and there was no recurrence of symptoms.

US-guided ESPB has a number of advantages, including a reduced risk of complications because it is away from pleural and neurological structures. ESPB can provide both thoracic and abdominal analgesia, depending on the level at which it is administered. [7] In some case reports and case series, ESPB provided abdominal analgesia when performed at the level of T7-T9. ${ }^{[7,8]}$ We performed ESPB in the present case because the patient experienced pain in the low thoracic and abdominal region. In common with the findings of the previous case report on ESPB during pregnancy, ${ }^{[6]}$ ESPB reduced the VAS score in our patient. Further prospective studies evaluating the analgesic effectiveness of ESPB in pregnant women are needed.
In conclusion, we conclude that ESPB may be used during pregnancy for postoperative analgesia management after laparoscopic procedures.

\section{References}

1. Juhasz-Böss I, Solomayer E, Strik M, \& Raspé C. Abdominal surgery in pregnancy-an interdisciplinary challenge. Dtsch Arztebl Int 2014;111(27-8):465-72. [CrossRef]

2. Skubic JJ, Salim A. Emergency general surgery in pregnancy. Trauma Surg Acute Care Open 2017;2:1-5. [CrossRef]

3. Upadya M, Saneesh PJ. Anaesthesia for non-obstetric surgery during pregnancy. Indian J Anaesth 2016;60(4):23441. [CrossRef]

4. Forero M, Adhikary SD, Lopez H, Tsui C, Chin KJ. The erector spinae plane block: a novel analgesic technique in thoracic neuropathic pain. Reg Anesth Pain Med 2016;41(5):621-7.

5. Tulgar S, Selvi O, Kapakli MS. Erector Spinae Plane Block for Different Laparoscopic Abdominal Surgeries: Case Series. Case Rep Anesthesiol 2018;2018:3947281. [CrossRef]

6. Restrepo-Garces CE, Urrego J, Mejia-Loaiza C, Giraldo L. The erector spinae plane block for radicular pain during pregnancy. Int J Obstet Anesth 2019;39:143-4. [CrossRef]

7. Restrepo-Garces CE, Chin KJ, Suarez P, Diaz A. Bilateral continuous erector spinae plane block contributes to effective postoperative analgesia after major open abdominal surgery: A case report. AA Case Rep 2017;9(11):319-21. [CrossRef]

8. Chin KJ, Malhas L, Perlas A. The erector spinae plane block provides visceral abdominal analgesia in bariatric surgery: a report of 3 cases. Reg Anesth Pain Med 2017;42(3):372-6. 